\title{
V. Note on fluid motion
}

\section{Rev. P. Kelland M.A. F.R.SS. L. \& E. F.C.P.S.}

To cite this article: Rev. P. Kelland M.A. F.R.SS. L. \& E. F.C.P.S. (1842) V. Note on fluid motion , Philosophical Magazine Series 3, 21:135, 29-33, DOI: 10.1080/14786444208621469

To link to this article: http://dx.doi.org/10.1080/14786444208621469

册 Published online: 01 Jun 2009.

Submit your article to this journal 준

LII Article views: 2

Q View related articles $₫$ 
I went from hence by Petherwin to the manyanese mine at " Bolathan," and there I observed the pale green killas had been sunk through by a vertical shaft to a depth of twentyfive feet (as I was informed) down to the Coddon Hill grit and its lode of manganese. The killas here is unequivocally exposed on the surface, and is an uninterrupted continuation of that which near Petherwin abounds in Clymeniæ, Goniatites, Orthoceratites, Trilobites, Orthides, \&c. \&c.; and if the subordinate grit had been carted to the spot from Coddon Hill in North Devon, or from St. Stephen's Down near Launceston, it could not have offered closer points of comparison and agreement.

The lower killas, the lowest of the threefold division into which that great member of the Devonian group naturally resolves itself, overlies the floriferous or carbonaceous series: not a shadow of doubt or uncertainty is on my mind when I state it ; the fact is proved by every variety and kind of recognized evidence by which the established order of superposition of rock formations has been determined elsewhere; and those several kinds of evidence cannot be disputed or rejected here without insecurity and peril to the foundations of the geological column, every stone of which has been hewed and squared and adjusted by some wise master builder. If in a perfect faith in, and uncompromising obedience to those laws which alone govern legitimate and secure induction, I have without pretension or design conveyed embarrassment or perplexity to the minds of some, or unkind or unworthy feelings to the minds of others, I am amply recompensed in the conscious indifference and singleness of purpose with which I have read off the great truths of the Creator, and in a dawn. of hope that, ere long, He may enable me to sound a diapason note which may restore to harmony the apparently discordant elements.

I have the honour to remain, \&c.
Bleadon, May 17, 1842.
D. Williams.

V. Note on Fluid Motion. By the Rev. P. Keli.and, M.A., F.R.SS. L. \& E., F.C.P.S., \&c., Professor of Mathematics in the University of Edinburgh, late Fellow and Tutor of Queen's College, Cambridge*.

THROUGH the able and interesting papers which Prof:

Challis has recently published in the Philosophical

Magazine $\dagger$, attention has been directed to the circumstances

* Communicated by the Author.

+ S. 3, vol. xix. p. 229. vol. xx. p. 84, 281. 
under which the equations of fluid motion can be solved: Whilst interest is awakened on the subject, it may not be deemed utterly unimportant to offer a few remarks on the general question, especially as any peculiarity in the mode of proceeding, however valueless in itself, may serve as a hint to guide or incite others to the most important investigations.

The question before us appears to me to be this-What new conditions must we introduce, or what transformations must we effect, in order that the four equations of fluid motion may be reduced to four other equations, each containing the differential coefficients of only one quantity? Before this question can be answered, at least before we can set about introducing any new conditions, it appears requisite to answer another question-Are there any necessary conditions? Of course the answer is in the affirmative. The equation of continuity is one. But it is not the only one; for unless the pressure and velocities are discontinuous quantities, the equations deduced by the application of D'Alembert's principle must be statical equations, depending on the time only in as far as the velocities depend on the time. Hence the relations which would exist amongst the differential coefficients of $p$, were the fluid at rest, must exist when it is in motion; that is,

$$
\frac{d^{2} p}{d x d y}=\frac{d^{2} p}{d y d x}, \text { \&c. }
$$

These, then, are equations of condition; the bearing of which ought to be examined previous to the introduction of any new conditions. They will serve, in some cases, to show what new hypotheses are admissible, and, in all, to detect those which are not.

It is not my intention to enter fully into this subject in my present communication. I shall content myself with offering a few remarks on the results of the mode of proceeding which I have indicated, as applied to the motion of incompressible fluids acted on by gravity only.

By inclosing within brackets the complete differentials with respect to $x, y, z$ and $t$, we obtain the following sets of equations :-

$$
\left.\begin{array}{l}
\left(\frac{d \mathrm{M}}{d t}\right)=\mathrm{M} \frac{d u}{d x}+\mathrm{N} \frac{d u}{d y}+\mathrm{P} \frac{d u}{d z} \\
\left(\frac{d \mathrm{~N}}{d t}\right)=\mathrm{M} \frac{d v}{d x}+\mathrm{N} \frac{d v}{d y}+\mathrm{P} \frac{d v}{d z} \\
\left(\frac{d \mathrm{P}}{d z}\right)=\mathrm{M} \frac{d w}{d x}+\mathrm{N} \frac{d w}{d y}+\mathrm{P} \frac{d w}{d z},
\end{array}\right\} \ldots
$$


or

$$
\left.\begin{array}{l}
\left(\frac{d \mathrm{M}}{d t}\right)=\mathrm{M} \frac{d u}{d x}+\mathrm{N} \frac{d v}{d x}+\mathrm{P} \frac{d w}{d x}, \\
\left(\frac{d \mathrm{~N}}{d t}\right)=\mathrm{M} \frac{d u}{d y}+\mathrm{N} \frac{d v}{d y}+\mathrm{P} \frac{d w}{d y}, \\
\left(\frac{d \mathrm{P}}{d t}\right)=\mathrm{M} \frac{d u}{d z}+\mathrm{N} \frac{d v}{d z}+\mathrm{P} \frac{d w}{d z} ;
\end{array}\right\}
$$

where

$$
\left.\begin{array}{rl}
\mathrm{M} & =\frac{d v}{d z}-\frac{d w}{d y} \\
\mathrm{~N} & =\frac{d w}{d x}-\frac{d u}{d z}, \\
\mathrm{P} & =\frac{d u}{d y}-\frac{d v}{d x}
\end{array}\right\} \ldots \ldots
$$

1. One way of satisfying all the equations is by supposing $\mathbf{M}=0, \mathrm{~N}=0, \mathbf{P}=0$; in which case the equations (3.) indicate that $u d x+v d y+w d z$ is a complete differential.

2. Another way is to suppose $\mathrm{M}, \mathrm{N}$ and $\mathrm{P}$ all absolutely constant; in which case the velocities $u, v$, $w$ will be determined by the same equation, viz. by either of the equations (1.). Hence $u, v, w$ all have the same form.

$$
\text { Also the equations (2.) give } \mathrm{M} \frac{d u}{d x}+\mathrm{N} \frac{d v}{d x}+\mathrm{P} \frac{d w}{d x}=0 \text {, }
$$

\&c. \&c., or $\mathrm{M} u+\mathrm{N} v+\mathrm{P} w$ is a quantity whose partial differential coefficients, with respect to each of the coordinates, is zero. This quantity is therefore either zero, or a function of $t$ only.

a. If it be zero, $u d x+v d y+w d z$ is integrable by a factor, for the equation $\mathrm{M} u+\mathrm{N} v+\mathrm{P} w=0$ is the wellknown equation of condition that this may be the case.

b. If $\mathbf{M} u+\mathrm{N} v+\mathrm{P} w=f(t), u d x+v d y+w d \approx$ is not a complete differential after being multiplied by a factor.

The equations are nevertheless integrable in this case, and give as their result,

$$
\begin{aligned}
& u=\mathrm{F}(\mathrm{M} z-\mathrm{P} x, \mathrm{~N} z-\mathrm{P} y, t) \\
& v=\Phi(\mathrm{M} z-\mathrm{P} x, \mathrm{~N} z-\mathrm{P} y, t), \\
& w=\psi(\mathrm{M} z-\mathrm{P} x, \mathrm{~N} z-\mathrm{P} y, t)
\end{aligned}
$$

* See my Memoir on the Theory of Waves, Trans. Roy. Soc. Edin., vol. xv. p. 116. 
the functions being subject to the condition $\mathrm{MF}+\mathrm{N} \phi+\mathrm{P} \psi$ $=f(t)$.

3. If $\mathrm{M}, \mathrm{N}, \mathrm{P}$ are explicit functions of $t$ only, our equations (1.) are reduced to

$$
\begin{aligned}
& \frac{d \mathrm{M}}{d t}=\mathrm{M} \frac{d u}{d x}+\mathrm{N} \frac{d u}{d y}+\mathrm{P} \frac{d u}{d z}, \\
& \frac{d \mathrm{~N}}{d t}=\mathrm{M} \frac{d v}{d x}+\mathrm{N} \frac{d v}{d y}+\mathrm{P} \frac{d v}{d z}, \\
& \frac{d \mathrm{P}}{d t}=\mathrm{M} \frac{d w}{d x}+\mathrm{N} \frac{d w}{d y}+\mathrm{P} \frac{d w}{d z} .
\end{aligned}
$$

Hence

$$
\begin{aligned}
& \mathrm{M} \frac{d^{2} u}{d x^{2}}+\mathrm{N} \frac{d^{2} u}{d x d y}+\mathrm{P} \frac{d^{2} u}{d x d z}=0 \\
& \mathrm{M} \frac{d^{2} u}{d x d y}+\mathrm{N} \frac{d^{2} u}{d y^{2}}+\mathrm{P} \frac{d^{2} u}{d y d z}=0 \\
& \mathrm{M} \frac{d^{2} u}{d x d z}+\mathrm{N} \frac{d^{2} u}{d y d z}+\mathrm{P} \frac{d^{2} u}{d z^{2}}=0
\end{aligned}
$$

from which equations we obtain, by eliminating $\mathrm{M}, \mathrm{N}$ and $\mathrm{P}$,

$$
\begin{aligned}
& \frac{d^{2} u}{d x^{2}} \frac{d^{2} u}{d y^{2}} \frac{d^{2} u}{d z^{2}}-\frac{d^{2} u}{d x^{2}}\left(\frac{d^{2} u}{d y d z}\right)^{2}-\frac{d^{2} u}{d y^{2}}\left(\frac{d^{2} u}{d x d z}\right)^{2} \\
& -\frac{d^{2} u}{d z^{2}}\left(\frac{d^{2} u}{d x d y}\right)^{2}+2 \frac{d^{2} u}{d x d y} \frac{d^{2} u}{d x d z} \frac{d^{2} u}{d y d z}=0 ;
\end{aligned}
$$

an equation of precisely the same form as that which occurs in the determination of the principal axes of a system, or of the diametral lines of a surface of the second order.

Similar equations are true in $v$ and $w$. We conclude that the motion is such as to be symmetrical with respect to the coordinate planes.

Cor.-If $x, y, z$ enter in such a way into the expressions for the velocities that $\frac{d u}{d y}=\frac{d u}{d z}, \& c$. , the equations are identically true.

4. If the motion be confined to two dimensions, the equations are reduced to

$$
\begin{aligned}
& \frac{d u}{d x}+\frac{d v}{d y}=0, \\
& \frac{d u}{d y}-\frac{d v}{d x}=\mathrm{C},
\end{aligned}
$$


where $C$ is a quantity whose total differential with respect to $t$ is zero.

$a$. If $\mathrm{C}$ be an absolute constant, the equations for determining $u$ and $v$ are

$$
\frac{d^{2} u}{d x^{2}}+\frac{d^{2} u}{d y^{2}}=0, \frac{d^{2} v}{d x^{2}}+\frac{d^{2} v}{d y^{2}}=0 .
$$

$b$. If $\mathrm{C}$ be not an absolute constant, the equation for $u$ assumes the following complicated shape:-

$$
\frac{d}{d y}\left\{\frac{\frac{d}{d y} \cdot \frac{\frac{d s}{d t}+u \frac{d s}{d x}-s \frac{d u}{d x}}{\frac{d u}{d y}}+\frac{d s}{d x}-\frac{\frac{d u}{d x} \frac{d s}{d y}}{\frac{d u}{d y}}}{\frac{d}{d y} \cdot \frac{\frac{d s}{d y}}{\frac{d u}{d y}}}\right\}=\frac{d u}{d x},
$$

where $s=\frac{d^{2} u}{d x^{2}}+\frac{d^{2} u}{d y^{2}}$.

The equation for $v$ is exactly similar to this.

It is unnecessary to add that this equation is too complicated to admit of integration in a general form.

We shall not prosecule these remarks further; we have offered them rather for the purpose of directing attention to the process than from a conviction of their novelty or importance.

VI. Experiments in Magneto-Electricity, illustrative of a Passage in Professor Faraday's Researches. By Professor Dove*.

FARADAY says, $\S 1101$, “ As an electric current acts by induction with equal energy at the moment of its commencement as at the moment of its cessation, but in a contrary direction, the reference of the effects of a current when stopped to an inductive action would lead to the conclusion, that corresponding effects of an opposite nature must occur in a long wire, a helix or electro-magnet, every time that contact is made with the electro-motor. These effects will tend to establish a resistance for the first moment in the long conductor, producing a result equivalent to the reverse of a shock or spark. Now it is very difficult to devise means fit for the recognition of such negative results." This difficulty may,

* Communicated by H. Croft, Esq., Teacher of Chemistry, being an extract from a letter addressed to him by the Author.

Phil.Mag. S. 3. Vol.21. No. 135. July 1842. D 